\title{
0.1T magnetic resonance image in the study of experimental hydrocephalus in rats. Accuracy of the method in the measurements of the ventricular size ${ }^{1}$
}

\author{
Imagem de ressonância magnética de 1,0T no estudo da hidrocefalia experimental em ratos. \\ Avaliação do método de medição do tamanho ventricular
}

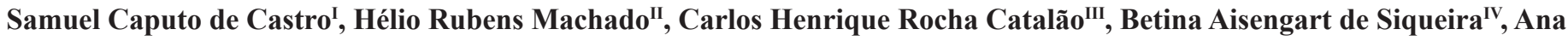 \\ Leda Bertoncini Simõesv, João-José Lachat ${ }^{\text {VI }}$ Luiza da Silva Lopes ${ }^{\text {VII }}$
}

IFellow PhD degree, Clinical Surgery Postgraduate Program, Department of Surgery and Anatomy, School of Medicine of Ribeirao Preto, USP, Ribeirao Preto-SP, Brazil. Acquisition and interpretation of data, surgical procedures, manuscript writing.

${ }^{I I}$ Full Professor, Division of Neurosurgery, Department of Surgery and Anatomy, School of Medicine of Ribeirao Preto, USP, Ribeirao Preto-SP, Brazil. Conception and scientific content of the study.

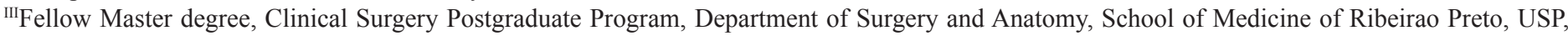
Ribeirao Preto-SP, Brazil. Acquisition and interpretation of data, manuscript preparation.

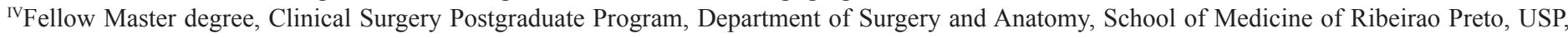
Ribeirao Preto-SP, Brazil. Handling of animals, collection and preparation of samples, initial drafts of the manuscript and statistical analysis.

${ }^{\mathrm{v} F e l l o w}$ PhD degree, Clinical Surgery Postgraduate Program, Department of Surgery and Anatomy, School of Medicine of Ribeirao Preto, USP, Ribeirao Preto-SP, Brazil. Acquisition and interpretation of data, manuscript preparation.

${ }^{\mathrm{V}}$ Associate Professor, Division of Neuroanatomy, Department of Surgery and Anatomy, School of Medicine of Ribeirao Preto, USP, Ribeirao Preto-SP, Brazil. Interpretation of data, analysis of samples, critical revision.

${ }^{\mathrm{VII}} \mathrm{PhD}$, Assistant Professor, Division of Neuroanatomy, Department of Surgery and Anatomy, School of Medicine of Ribeirao Preto, USP, Ribeirao Preto-SP, Brazil. Main author. Conception, design and scientific content of the study, critical revision.

\begin{abstract}
PURPOSE: To investigate the accuracy of 1.0T Magnetic Resonance Imaging (MRI) to measure the ventricular size in experimental hydrocephalus in pup rats.

METHODS: Wistar rats were subjected to hydrocephalus by intracisternal injection of $20 \%$ kaolin ( $\mathrm{n}=13$ ). Ten rats remained uninjected to be used as controls. At the endpoint of experiment animals were submitted to MRI of brain and killed. The ventricular size was assessed using three measures: ventricular ratio (VR), the cortical thickness (Cx) and the ventricles area (VA), performed on photographs of anatomical sections and MRI.
\end{abstract}

RESULTS: The images obtained through MR present enough quality to show the lateral ventricular cavities but not to demonstrate the difference between the cortex and the white matter, as well as the details of the deep structures of the brain. There were no statistically differences between the measures on anatomical sections and MRI of VR and Cx ( $p=0.9946$ and $p=0.5992$, respectively). There was difference between VA measured on anatomical sections and MRI $(\mathrm{p}<0.0001)$.

CONCLUSION: The parameters obtained through 1.0T MRI were sufficient in quality to individualize the ventricular cavities and the cerebral cortex, and to calculate the ventricular ratio in hydrocephalus rats when compared to their respective anatomic slice.

Key words: Hydrocephalus. Magnetic Resonance Imaging. Rats.

\section{RESUMO}

OBJETIVO: Investigar a fidelidade das Imagens de Ressonância Magnética de 1,0T no estudo do tamanho ventricular na hidrocefalia experimental em ratos jovens.

MÉTODOS: Ratos Wistar foram submetidos à hidrocefalia através da injeção intracisternal de caulim 20\%. Dez animais permaneceram sem injeção para uso como controles. Ao final do experimento, os animais foram submetidos à Ressonância magnética de encéfalo e sacrificados. O tamanho ventricular foi avaliado por três medidas: razão ventricular (VR), espessura cortical (Cx) e área ventricular 
(VA), tomadas em fotografias das secções anatômicas e nas imagens de ressonância magnética (RM).

RESULTADOS: As imagens por RM apresentaram qualidade suficiente para individualizar os ventriculos laterais, mas a distinção entre córtex e substância branca, bem como detalhamento das estruturas profundas do encéfalo não foram possíveis. Quando comparadas as medidas em seções anatômicas e RM, não houve diferença estatística entre as médias de razão ventricular e espessura cortical ( $p=0,9946$ e p=0,5992, respectivamente). Houve diferença da área ventricular comparando-se as secções anatômicas e ressonância magnética $(\mathrm{p}<0,0001)$.

CONCLUSÃO: Os parâmetros obtidos através de imagens da ressonância magnética de 1,0T foram suficientes para individualizar as cavidades ventriculares e o córtex cerebral, e para calcular o tamanho ventricular em ratos hidrocefálicos quando comparados aos seus respectivos cortes anatômicos.

Descritores: Hidrocefalia. Imagem por Ressonância Magnética. Ratos.

\section{Introduction}

Hydrocephalus is a state at which the circulation of cerebrospinal fluid (CSF) is disturbed. This fluid, produced within the brain at a constant rate, moves through the ventricles, then exits them so that it may be absorbed by the venous system. Should the fluid fail to move properly through the ventricles, the result would be the distention of the cavities which would cause displacement and distortion of the brain tissue ${ }^{1}$. It was possible to establish a sequence of events in the evolution of the disease through studies with experimental hydrocephalus. In the first stage of the ventricular dilation there is an increase of permeability of the ependyma to CSF with changes in itself and stretching and compression of periventricular tissue and blood vessels mainly in the white matter ${ }^{2,3}$. Often, the Magnetic Resonance Imaging is the choice method to value the ventricular size in the experimental hydrocephalus. However, the accuracy of imaging is not known for apparatus of $1.0 \mathrm{~T}$ field. The purpose of this study was to test the accuracy of the Magnetic Resonance of 1.0T to measure the ventricular size in experimental hydrocephalus in juvenile rats.

\section{Methods}

All animals were treated in accordance with guidelines by the COBEA (Brazilian College of Animal Experimentation) and protocols were approved by the local animal ethics committee (CETEA), protocol \# 050/2009.

Twenty three animals were randomly divided into two groups: control $(\mathrm{n}=10)$ and hydrocephalus $(\mathrm{n}=13)$. These animals were kept under constant environmental conditions. Animals were housed in standard cages with ten pups and a surrogate mother into each one, and proper diet and water ad libitum were offered. All efforts were made to minimize suffering and the number of animals used.

For hydrocephalus induction, an odonthological needle with short bevel was percutaneously inserted into the cisterna magna of seven days-old male rats and $0.04 \mathrm{ml}$ of $20 \%$ sterile kaolin $\left(\right.$ Merck $\left.^{\circledR}\right)$ suspension diluted in distilled water was injected slowly. The controls did not receive any injection. At 14, 21, 28 or 35 days after the injection the animals were submitted to Magnetic Resonance Imaging and killed (up to 12 hours after the MRI) by anesthesia with Ketamine $90 \mathrm{mg} / \mathrm{Kg}$ (Ketamina ${ }^{\circledR}$-Pfizer do Brasil Ltda) associated with Xylazine $10 \mathrm{mg} / \mathrm{Kg}$ (Rompum ${ }^{\circledR}$-Bayer do Brasil Ltda), intramuscularly. In this study it was used an apparatus of 1.0T field with head bobbin and skull transversal slices in $\mathrm{T} 1$ sequence with $\mathrm{TR}=260 \mathrm{~ms}, \mathrm{TE}=20 \mathrm{~ms}$ and TA $=1.18 \mathrm{~s}$. After the exam the animals were perfused intracardially with saline solution followed by $10 \%$ formaldehyde. Their brains were removed from the skull and sectioned in coronal slices similar to the Magnetic Resonance Imaging. The brain sections were photographed and the images were compared with ones obtained for Magnetic Resonance Imaging using the Image J software (NIH 1.38x Wayne Rasband). Three measures were taken to assess the size of the ventricles, the ventricular ratio (VR), the cortical thickness $(\mathrm{Cx})$ and the ventricles area (VA). The VR was measured dividing the greater distance between the walls of the ventricles and the distance at the same level, between the corresponding cortical areas. The $\mathrm{Cx}$ considered was an average of measurements made in the lower cortical thickness of both hemispheres. And the AV was considered as the sum of the areas included in the contours of the ventricles. All measurements were made on digital photographs of anatomical sections (AS) and radiographs of MRI.

The association degree between measurements of the ventricular ratio in the anatomical slice (VR-AS) and ventricular ratio in the magnetic resonance imaging (VR-MR); and between cortical thickness in the anatomic slice $(\mathrm{Cx}-\mathrm{AS})$ and cortical thickness in the magnetic resonance imaging (Cx-MR); and between ventricular area in the anatomic slice (VA-AS) and ventricular area in the magnetic resonance imaging (VA-MR) was evaluated by means of correlation coefficient. A regression 
equation was used to describe the behavior of one measurement in function of other. The comparison among measurements VRAS and VR-MR, Cx-AS and Cx-MR, and VA-AS and VA-MR was carried out with the Student's $t$ test for parametric data. Two parameters have been set up to evaluate the data, which are the average of differences between the measurements in MR and the in the AS, and the percentage of average difference between the same measurements. The differences of VR, Cx and VA were defined as the measurements in their MR photography minus the measurement in the photography of AS (MR measurement-AS measurement). The percentage difference of those measurements was defined as the difference divided by the measurement in AS photography (MR measurement-AS measurement / AS measurement).

Statistical analysis was performed using paired t-test to compare VR, Cx and VA between MRI and brain slices. The degree of difference between MRI and brain slice was calculated by regression analysis. Significant statistical difference was considered when $p<0.05$.

\section{Results}

The variation between the values minimum (MIN) and maximum (MAX) of VR, Cx and VA in the AS and in the MR, and the correlation coefficient $(\mathrm{X})$ between measurements are show in the Table 1.

TABLE 1 - Variation between the values of VR, Cx and VA minimum (MIN) and maximum (MAX) in the AS and in the MR and the correlation coefficient (X).

\begin{tabular}{|c|c|c|c|}
\hline & MIN & MAX & $\mathbf{X}$ \\
\hline VR-AS & $0.3967 \mathrm{~mm}$ & $0.8213 \mathrm{~mm}$ & \\
\hline VR-MR & $0.4174 \mathrm{~mm}$ & $0.8720 \mathrm{~mm}$ & 0.9563 \\
\hline Cx-AS & $0.3485 \mathrm{~mm}$ & $2.4030 \mathrm{~mm}$ & \\
\hline Cx-MR & $0.5845 \mathrm{~mm}$ & $2.1310 \mathrm{~mm}$ & 0.6101 \\
\hline VA-AS & $3.9230 \mathrm{~mm}^{2}$ & $68.6180 \mathrm{~mm}^{2}$ & \\
\hline VA-MR & $8.8400 \mathrm{~mm}^{2}$ & $82.8330 \mathrm{~mm}^{2}$ & 0.8559 \\
\hline
\end{tabular}

Student's $t$ test for data to VR-AS and VR-MR supplied a p-value of 0.9946 determining that there is not statistically significant difference between the averages of the VR of the two objects measured (Figure 1). To Cx-AS and Cx-MR the test supplied a p-value of 0.5992 determining that there is not statistically significant difference between the averages of the $\mathrm{Cx}$ of the two objects measured (Figure 2). To VA-AS and VA-MR it supplied a $p$-value $<0.0001$ determining that there is difference significant statistically between the averages of the VA of the two objects measured (Figure 3 ).

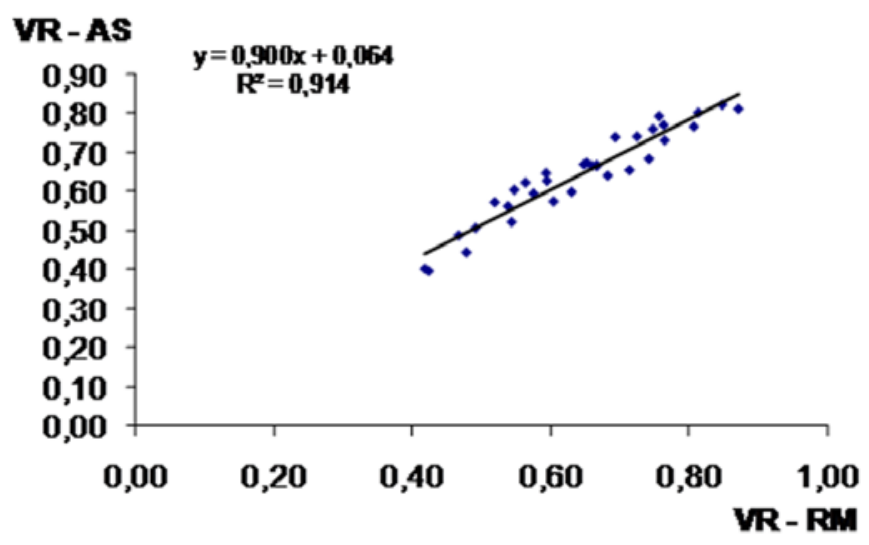

FIGURE 1 - Regression analysis for the values of Ventricular ratio measured in anatomical cuts (VR-AS) and Magnetic Resonance (VR$\mathrm{MR}$ ) in hydrocephalic rats. $\mathrm{R}^{2}=$ coefficient of determination.

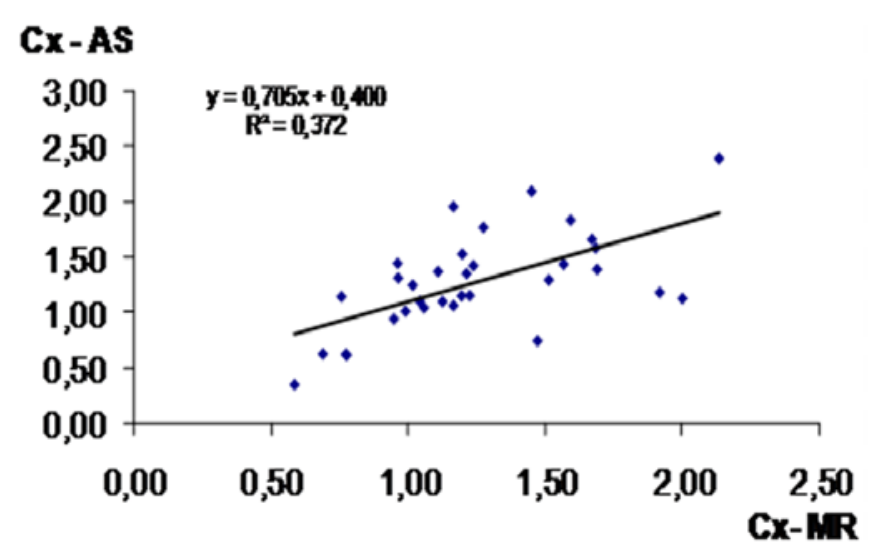

FIGURE 2 - Regression analysis for the values of cortical thickness measured in anatomical cuts $(\mathrm{Cx}-\mathrm{AS})$ and $\mathrm{MRI}(\mathrm{Cx}-\mathrm{RM})$ in hydrocephalic rats. $R^{2}=$ coefficient of determination.

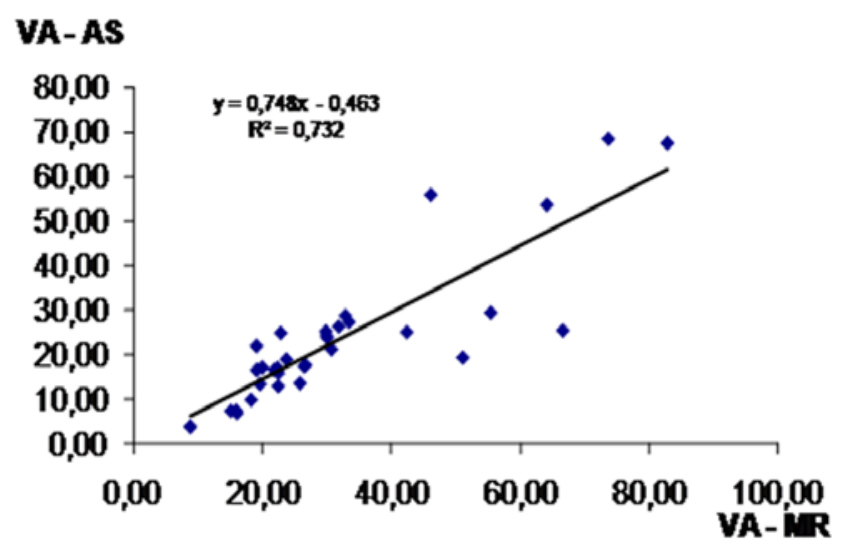

FIGURE 3 - Regression analysis for the values of the ventricular area measured in anatomical cuts (VA-AS) and Magnetic Resonance Imaging (VA-MR) in hydrocephalic rats. $\mathrm{R}^{2}=$ coefficient of determination. 
The images obtained through MR present enough quality to show the lateral ventricular cavities but not to demonstrate the difference between the cortex and the white matter as well as the details of the deep structures of brain (Figure 4).

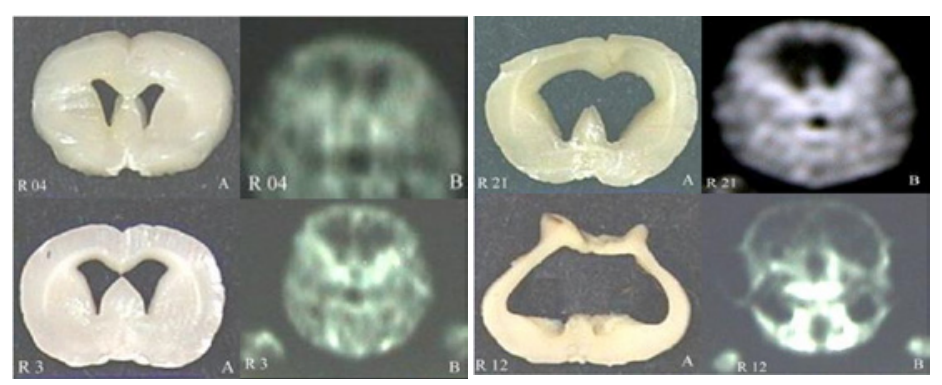

FIGURE 4 - Coronal anatomical slices of rat brain (A) and MRI of same animal (B) with discrete ventriculomegaly (R04), moderate ventriculomegaly (R3), severe ventriculomegaly (R21) and maximum ventriculomegaly (R12).

\section{Discussion}

MRI has been used frequently to measure the ventricular size in human patients as well as in experimental hydrocephalus. Many who work with animals for experimentation use high-field equipment to evaluate this dilation. However, such equipment is costly and not readily available. Moreover, for medical clinical examinations, 1.0 or $1.5 \mathrm{~T}$ are very widespread. In this study, we tested the reliability of the images obtained from a $1.0 \mathrm{~T}$ field equipment in the evaluation of ventricular size. Ling and Lees $^{4}$ found that in the past 20 years, magnetic resonance has had great impact in facilitating accurate diagnosis, and now they used eight case vignettes to illustrate how MRI findings can assist in the diagnosis of movement disorders and, in some cases, change the course of patient management.

An extremely important factor observed in MRI is the periventricular edema, a well-known feature of hydrocephalus. With MRI the differentiation of edema depends on the imaging parameters used, because this edema may produce an overestimation of the ventricle volume and can lead to errors in volume and length calculations. In this study, the greater measures of the ventricle area (VA) obtained by the MRI in vivo might be due to the fact that such examination included periventricular edema areas in the measurement process. Dehydration of the anatomic piece on account of formaldehyde may also be counted as another factor ${ }^{5}$.

Others authors ${ }^{6}$ revealed a strong linear correlation between the values of the apparent diffusion coefficient (ADC) and the aquaporin 4 (AQP4) expression in the periventricular edema associated to communicative hydrocephalus in adult rats, using 1.5T MRI. Their study proved the important role that AQP4 plays as an adapting response to the ventricular expansion through the activation of new membrane receptors and the consequent edema decrease. This discovery was justified as of demonstrating a direct correlation between accelerate water self-diffusion measured by MRI and the augmented aquaporin 4 expression. Researchers demonstrated through Magnetic Resonance Angiography that the Cerebral Blood Flow (CBF) is directly related to the ADC in infants with compensate hydrocephalus and in children with slowly progressive hydrocephalus. The authors suggested that hydrocephalus can't be diagnosed without a magnetic resonance image and also that the $\mathrm{CBF}$ and $\mathrm{ADC}$ values contribute in a noninvasive way to the decision-making process ${ }^{7}$.

According to one study was undertaken to develop a technique to monitor and quantify progressive changes in ventricle and cortical dimensions in hydrocephalic rats in vivo. $4.7 \mathrm{~T}$ Magnetic Resonances Images were obtained with a T1-weight protocol and multislice variant of the inversion recovery sequence which displayed optimal contrast between cerebrospinal fluid and brain parenchyma. They concluded that MRI can be used for measuring the progress of hydrocephalus in postnatal rats through quantification of the changes in brain and ventricular structures ${ }^{6}$.

Other study found, that made comparison between cutting anatomical and magnetic resonance, employed 0.3T MRI to follow more accurately the progression of ventriculomegaly, as well as to evaluate the compensatory effects of VP shunting. They concluded that these results indicated that Magnetic Resonance Imaging is an excellent method for visualizing the morphological changes in the brain ${ }^{8}$.

In like manner, one work when applying 4.2T Magnetic Resonance in newborn felines with experimental hydrocephalus proved the sensitivity of the image exam in detecting countless morphologic changes as a result of ventriculomegaly in the acute and chronic illness phases. A region of the periventricular white matter was completely edematous, while the cortex gray matter was found stretched and flattened. The back of the internal capsule member, where there is optic radiation, was stretched and edematous. There was an important loss in the visual cortex in the chronic hydrocephalus case and it was impossible to differentiate the periventricular white matter from the grey matter. Furthermore, the internal capsule was completely torn apart and disconnected from the occipital cortex. Also, the MRI showed that the cerebrospinal fluid shunt was efficient, for it reduced considerably the ventricular size in both of the investigated groups. In some cases, the lateral ventricles returned to their 
normal size 9 . Other work findings also verify the efficacy of MRI as a diagnosis resource of hydrocephalus. As they investigate the morphologic changes occurred in juvenile and young adult mice as a result of hydrocephalus, the authors concluded that MRI is a reliable method to investigate the ventricular size. By using a $7 \mathrm{~T}$ device it was possible to notice modification in the periventricular matter, mostly in the external capsule, and wide expansion of the fourth ventricle. Moreover, it was possible to differentiate the ventriculomegaly degree in both animal groups. In the juvenile mice, the ventriculomegaly was more severe than the one present in the young adults ${ }^{10}$.

Undoubtedly, the neuroimage exam is a resource of extreme importance in the diagnosis and prognosis of different kind of illnesses. Nowadays, magnetic resonance is already being used associated with other resources to aim of investigating pathophysiological characteristics of several diseases, mainly the neurological ones ${ }^{11-13}$. However, most studies, both experimental and clinical, use MRI equipment of field higher than 1.0T. These devices, however, are not always available for use in animal experimentation in Brazil. Our study showed that 1.0T MRI is a reliable equipment to measure the ration ventricle in experimental hydrocephalus.

However, specific studies are necessary in order to improve the quality of magnetic resonance images to allow the visualization not only of the ventricular size, but also of the anatomic details of the deep brain structures so that potential changes caused by the disease may be detected.

\section{Conclusion}

The parameters obtained through 1.0T MRI were sufficient in quality to individualize the ventricular cavities and the cerebral cortex, and to calculate the ventricular ratio in hydrocephalus rats when compared to their respective anatomic slice.

\section{References}

1. Kaczmarek M, Subramaniam RP, Neff SR. The hydromechanics of hydrocephalus: steady-state solutions for cylindrical geometry. Bull Math Biol. 1997;59(2):295-323.

2. Yamada H, Yokota A, Furuta A, Horie A. Reconstitution of shunted mantle in experimental hydrocephalus. J Neurosurg. 1992;76(5):85662.

3. Del Bigio MR, Bruni JE. Silicone oil-induced hydrocephalus in the rabbit. Childs Nerv Syst. 1991;7(2):79-84.

4. Ling H, Lees AJ. How can neuroimaging help in the diagnosis of movement disorders? Neuroimaging Clin N Am. 2010;20(1):11123.
5. Harris NG, Jones HC, Williams SC. MR imaging for measurements of ventricles and cerebral cortex in postnatal rats (H-Tx strain) with progressive inherited hydrocephalus. Exp Neurol. 1992;(1)118:1-6.

6. Tourdias T, Dragonu I, Fushimi Y, Deloire MS, Boiziau C, Brochet B, Moonen C, Petry KG, Dousset G. Aquaporin 4 correlates with apparent diffusion coefficient and hydrocephalus severity in the rat brain: a combined MRI-histological study. Neuroimage. 2009;47(2):659-66.

7. Leliefeld PH, Gooskens RH, Tulleken CA, Regli L, Uiterwaal CS, Han KS, Kappelle LJ. Noninvasive detection of the distinction between progressive and compensated hydrocephalus in infants: is it possible? J Neurosurg Pediatr. 2010;5(6):562-8.

8. McAllister JP, Cohen MI, O'Mara KA, Johnson MH. Progression of experimental infantile hydrocephalus and effects of ventriculoperitoneal shunts: an analysis correlating magnetic resonance imaging with gross morphology. Neurosurgery. 1991;29(3):329-40.

9. Eskandari R, Harris CA, McAllister JP. Reactive astrocytosis in feline neonatal hydrocephalus: acute, chronic, and shunt-induced changes. Childs Nerv Syst. 2011;27(12):2067-76.

10. Lopes LS, Slobodian I, Del Bigio MR. Characterization of juvenile and young adult mice following induction of hydrocephalus with kaolin. Exp Neurol. 2009;219(1):187-96.

11. Leliefeld PH, Gooskens RH, Vincken KL, Ramos LM, van der Grond J, Tulleken CA, Kappelle LJ, Hanlo PW. Magnetic resonance imaging for quantitative flow measurement in infants with hydrocephalus: a prospective study. J Neurosurg Pediatr. 2008;2(3):163-70.

12. Vavasour IM, Laule C, Li DK, Traboulsee AL, MacKay AL. Is the magnetization transfer ratio a marker for myelin in multiple sclerosis? J Magn Reson Imaging. 2011;33(3):713-8.

13. Jadhav V, Sugawara T, Zhang J, Jacobson P, Obeanus A. Magnetic resonance imaging detects and predicits early brain injury after subarachnoid hemorrhage in a canine experimental model. J Neurotrauma. 2008;25(9):1099-106.

\section{Correspondence:}

Luiza da Silva Lopes

Departamento de Cirurgia e Anatomia

Faculdade de Medicina de Ribeirão Preto

Universidade de São Paulo

Avenida Bandeirantes, 3.900

14040-905 Ribeirão Preto - SP Brasil

Tel.: (55 16)3602-4690

luslopes@.fmrp.usp.br

Received: June 28, 2012

Review: August 29, 2012

Accepted: September 26, 2012

Conflict of interest: none

Financial source: FAEPA (Foundation to Support Education, Research and Care at the Clinics Hospital, School of Medicine of Ribeirao Preto, USP).

${ }^{1}$ Research performed at Laboratory of Neuroanatomy, Department of Surgery and Anatomy, School of Medicine of Ribeirao Preto, University of Sao Paulo (USP), Ribeirao Preto-SP, Brazil. Tutor: Luíza da Silva Lopes. 